[Penetito, W. (1993). The Audit and Review of Maori Education in the Compulsory Schooling Sector. New Zealand Annual Review of Education, $2,225-243]$

\section{The Audit and Review of Maori Education in the Compulsory Schooling Sector}

\section{WALLy PENETITO}

卫

his chapter is an analysis of the audit and review findings of Maori education in schools as conducted by the Education Review Office throughout 1992.

Audit and review are two different processes of evaluation which focus on different things and yield different but complementary data. Whereas review methodology depends a lot on structured interviews and questionnaires, audit is concerned that evidence should come from authoritative documented sources.

The chapter describes and explains both procedures in the context of evaluating Maori education provision. It summarises the information gained and provides both an interpretation of what was learned and a guide as to how the evaluation of Maori education might be improved.

\section{The Role and Functions of the Education Review Office in the School} Sector (Education Review Office, 1992-1)

Operating within the executive sector of the State, the Education Review Office provides, in effect, an internal audit and quality assurance function for the Crown in respect of its education interests.

Its powers extend to cover educational organisations in the pretertiary sector, and the Chief Review Officer has a duty to report independently to the Minister on all matters where quality assurance is required, or deemed appropriate by that Officer.

The functions of the Office are best described in terms of a model. The three critical elements in the education sector, from the perspective of the Education Review Office are:
226 Wally Penetito

- The Crown, as owner/investor, purchaser and regulator.

- The Board of Trustees, which has a contractual relationship with the Crown:

a to manage Crown-owned assets located in school property; and

$\mathrm{b}$ to provide specific services for a class of consumers including those who, between the ages of 5 and 16, are compelled by regulation to participate in services provided by State-licensed suppliers.

- The Consumer: The Student, who may be regarded as the primary and intended beneficiary of State regulation.

\section{Role of the Education Review Office}

The Office is employed by the Crown to provide the responsible Minister with two specific forms of report:

i assurance as to the accountability of Boards of Trustees, in terms of their contractual undertakings with the Crown; and

ii evaluative analysis of the performance of Boards of Trustees, in terms of the value their services add to the educational satisfaction of the primary consumer - the student. Educational satisfaction is defined by the Crown in terms of students' achievement and progress.

\section{Reporting on Accountability}

The Office undertakes Assurance Audits which provide an opinion as to the extent to which the parties, namely, the Ministry of Education and Board of Trustees, meet the terms of their contractual relationship. The focus of attention, given that the Crown has engaged the Office for this purpose, is on the accountability of the Trustees.

The independence of the Office from both parties during the conduct of an assurance audit is critical to the level and quality of assurance provided. The Chief Review Officer determines both the scope and the manner in which assurance is to be provided, and faces the normal liability attaching to any similar audit activity in the commercial field. 


\section{Reporting on Educational Service Delivery Performance}

Reports on service delivery start from the perspective of the student, and ask of the Boards how they define consumer satisfaction, in terms of progress and achievement.

The analysis which follows then identifies the range of factors which, in the judgement of the reviewer, are regarded as effecting specific levels of student achievement or under-achievement.

While these factors are likely to include a conventional range of typical factors such as the performance of key managers, organisational structure, level and management of resources, quality of teaching service and so forth, there will normally be unique factors pertaining to the individual school.

These reports are what the Education Review Office calls Effectiveness Reviews. An Effectiveness Review will involve a direct review of an educational institution in order to provide an in-depth analysis and evaluation of its effectiveness. The review will provide information about the institution in operation, from the viewpoint of the contribution it makes to the educational outcomes of its students (in terms of both standards and progress).

An Effectiveness Review of an institution will examine evidence of outcomes (achievement), the quality of service delivery (provision of learning opportunities) and the quality of management systems, policies and practices, and analyse the relationships between these aspects of performance.

Good practices and barriers to learning will be identified and an opinion about the effectiveness of the institution provided.

Where possible, the Effectiveness Review will indicate a causal relationship between student achievement and service-related factors, in a diagnostic rather than prescriptive manner.

Responsibility for action remains with the contract parties. The independence of the Office is critical to its ability to comment, directly or publicly, to the parties, and to recommend sanctions where appropriate.

\section{The Role of the Education Review Office in the Evaluation of Maori}

\section{Education}

If Maori education is simply defined as the schooling of Maori students and about Maori culture, then the audit and review of Maori education as carried out by the Office is the same in substance as that carried out for all other schools and centres. Audit and review of Maori education provision will differ only in those areas that clearly differentiate them from the mainstream, that is, medium of communication and instruction and the imperative to observe distinctly Maori protocols and procedures. In these cases, audit and review teams will be led by Maori speaking reviewers and they will be familiar with the particular kaupapa of the centre/school.

\section{How Can Assurance Audits Help in the Evaluation of Maori Education?}

Assurance audits concentrate on service delivery and management practice, that is, those things for which the institution may be held directly accountable.

The Education Review Office (1992-2) has set out the kind of contractual obligations and undertakings for which reviewers search for evidence of compliance or non-compliance. Here are four such requirements:

i Under Governance and Management Systems and Practices there are sections within the Charter Framework and the Education Act 1989 which state that Boards of Trustees must:

- take all reasonable steps to discover and consider the views and concerns of the Maori community;

- use the Maori communities' own processes to consult; and

- take all reasonable steps to discover and consider the views and concerns of the local Maori communities.

ii Under the Charter sections related to the Treaty of Waitangi Goals and Objectives, Guiding Principles, and Code of Conduct it is required that Boards of Trustees ensure that policies are prepared and implemented to: 
- ensure the curriculum reflects Maori perspectives;

- make equitable provision for the instructional needs of Maori children;

- provide opportunities for students who wish to learn Maori language and culture;

- provide for students whose parents wish them to be educated through te reo Maori;

- recognise Maori values in the provision of resources and facilities within the school; and

- staff the school to meet the requirements of the above.

iii Under Personnel Management Boards of Trustees are required to recognise:

- the aims and aspirations of Maori;

- the employment requirements of Maori; and

- the need for greater Maori involvement in the education service.

iv Under Curriculum Management and Implementation sections Boards of Trustees are required to:

- ensure that every child is aware of the dual cultural heritage of New Zealand and the multicultural nature of our society;

- ensure that practices recognise Maori learning needs; and

- ensure that the curriculum fulfils the intent of the Treaty of Waitangiby valuing and reflecting New Zealand's dual cultural heritage.

During assurance audits reviewers search for evidence for compliance against requirements by examining documents, talking to people involved, making observations before making judgements on the basis of the quality of evidence discovered. Reviewers also need assurances about what counts as evidence for every requirement. The training and guidance they receive is critical if assurances are to have any credibility.
They then prepare an assurance audit report for the governing body and for the Minister responsible for the Education Review Office. When the audit is confirmed the information becomes public.

Analyses and evaluations which arise from assurance audits will be extremely important for improving the quality of Maori education right across the educational sector because they address the fundamental question "are you providing the service that you have agreed to provide in the manner, and to the level set out in your 'contract' with the purchaser of the service?" The generally abysmal standards currently prevailing in Maori education will undoubtedly improve with this extra attention to what must be the absolute basic requirement of schools, that is, their reason for existing.

\section{How Can Effectiveness Reviews Help in the Evaluation of Maori Education?}

Effectiveness reviews focus on educational outcomes, that is, learning and achievement standards and progress. They will determine why certain standards and progress are achieved by identifying contributing factors which are within the schools' control.

Because of the need for documentation of achievement standards and progress, effectiveness reviews are restricted to the compulsory years of schooling. These outputs will not begin until sometime early in 1993. (It should be carefully noted that "reviews" referred to in reports analysed below are not "Effectiveness Reviews" but they are more akin to Effectiveness Reviews than they are to Assurance Audits.)

\section{Review Findings on Maori Education}

The Office has been in operation for over three years since its formal establishment in October 1989.

To date, it has reviewed the performance of almost 5,000 institutions, including:

$\begin{aligned} 2,700 & \text { early childhood centres } \\ 1,800 & \text { primary schools } \\ 340 & \text { secondary schools } \\ 63 & \text { private schools. }\end{aligned}$

By the end of 1993 the Office will have reviewed all Crown-owned and privately-owned educational agencies in the school sector at least once. 
Under this section, reports from 195 separate school audits and reviews have been analysed and presented as findings from three aggregated reports.

Report 1 was based on 66 reviews of primary and secondary schools from around the country. The methodology for reviewing was as adopted for 1991 and the first half of 1992 (Penetito, Glasson and Thew, 1991) and therefore prior to either assurance audits, which began in July 1992 or Effectiveness Reviews which are due to commence in March 1993. The methodology was an earlier version of Effectiveness Reviews with reports being delivered under five headings: student achievement, learning and teaching, assessment and evaluation, leadership and management, and community participation.

Report 2 was based on an analysis of 29 secondary school review reports carried out between July and September 1992. The Review Office at this time, in terms of the methodology it was using, was in transition between the approach used as in Report 1 and the developing standard procedures for assurance audits.

Report 3 is an analysis of 100 review reports of primary and integrated schools carried out in July and September 1992. The methodology being used was as in Report 2, that is, the initial development of standard procedures for assurance audits.

\section{Report 1 [Education Review Office, 1992-3]}

In 1992 the Office conducted an internal audit of Review Information on Maori and Maori Learners. A sample was selected from lists of reviews supplied by the districts. These are the findings from that report:

\section{Finding 1}

With respect to the "identification of Maori students and their educational achievement":

- many schools have systems for data collection to identify Maori students and their achievement;

- overall, the identification of Maori as a (target equity) group is lacking;
- in most schools, even those where data collection is relatively routine, better use could be made of the data to inform decisions on student achievement and programme effectiveness.

\section{Finding 2}

With respect to the "provision of specific educational programmes for Maori students" and "the improvement of the quality of delivery to Maori students":

- there are significant variations in the resources available for programmes across the country, in particular the existence of adequate numbers of teachers who are fluent speakers of Maori was seen to be a major concern;

- programmes are largely not being evaluated, and neither are the role, contributions or expectations of personnel such as kaiarahi reo and resource teachers of Maori.

\section{Finding 3}

With respect to the "inclusion of specific Maori elements within learning programmes" and "the recognition of Maori within the environment of the school":

- programmes which are being run reflect te reo me nga tikanga Maori to varying degrees;

- while many school environments reflect an extent of te ao Maori and New Zealand's dual cultural heritage, there is room for considerable improvement.

\section{Finding 4}

With respect to the "consultations with Maori parents and caregivers":

- consultation with Maori parents and caregivers occurs frequently and successfully;

- consultation with iwi Maori is less frequent but often very rewarding. 
This report also revealed a number of features which could be identified as successes or effectiveness criteria for the learning and achievement of Maori students.

\section{Finding 5}

With respect to the involvement of the Maori community with schools, success was observed when:

- whanau were supportive and committed to the kaupapa;

- there was a close relationship with iwi;

- good relationships with Te Kohanga Reo existed.

\section{Finding 6}

With respect to the governance of the school, success was observed when:

- there were clear guidelines on community reporting;

- policies reflected Maori parents' views.

\section{Finding 7}

With respect to the Staff/Resources of the school, success was observed when:

- $\quad$ staff were well trained (culturally);

- staff were aware of Maori learning styles;

- teachers had consistently high expectations of Maori;

- a teacher with overall responsibility for Maori in the curriculum was available to assist other teachers.

\section{Finding 8}

With respect to the pupils and programmes, success was observed when:

- programmes were well planned and effectively delivered;

- whanau, teina/tuakana, peer relationships were natural elements of programmes;

- an appropriate cultural venue (marae, wharenui) existed within the school environment.

\section{Finding 9}

With respect to the school environment, success was observed when:

- an appropriate cultural base (marae, whare awhina) was present;

- classroom environments reflected the dual cultural heritage;

- Maori protocol was accepted and valued.

A final important cluster of findings from this report relates to barriers to the successful learning and achievement of Maori students.

\section{Finding 10}

With respect to the involvement of Maori communities with schools, barriers to success were observed when:

- tangata whenua resources were under-utilised;

- no strong links with local marae/iwi existed.

\section{Finding 11}

With respect to the governance of the school, barriers to success were observed when:

- Maori trustees felt they had an additional cultural load other trustees didn't have; 
- community consultation was ineffective;

- the school had trouble attracting skilled/trained staff;

- effective evaluation of programmes/teachers was lacking.

\section{Finding 12}

With respect to staff and resources, barriers to success were observed when:

- fluent speakers were lacking;

- personnel were under-trained;

- no teacher had responsibility or took the lead;

- support systems were unidentified and not used (e.g., Resource Teachers, Maori Advisory Services);

- teachers in other curriculum areas did not consolidate te reo me nga tikanga Maori.

\section{Finding 13}

With respect to pupils and programmes, barriers to success were observed when:

- $\quad$ resources were scarce;

- a deep understanding of te ao Maori was not evident in the school.

\section{Finding 14}

With respect to Maori within the environment of the school, barriers to success were observed when:

- appropriate role models were lacking (Maori, male Maori, Maori women, women);

- school was not seen to be valuing or strengthening the Maori side of pupils' dual cultural heritage.

\section{Report 2 [Education Review Office, 1992-4]}

An analysis of 29 secondary school review reports conducted nationally between July and September 1992 revealed a number of supportive statements about practices which are contributing to Maori student achievement. These are:

- Maori students who reach Form 7 achieve well;

- the school is encouraging Maori students to set their sights on postschool goals that match abilities and potential;

- Maori trustee members, whanau group and Maori teachers are working collaboratively;

- school has high expectations of Maori learners;

- curriculum development work to meet specific needs of Maori learners is a big plus;

- bilingual programmes are proving to be highly successful in motivating students;

- Maori learning and teaching methodologies are being used to great effect;

- production of written resources in Maori for a range of academic disciplines is making a major contribution to a Maori knowledge base for school use;

- identification and evaluation of specifically Maori sources of knowledge is a critical factor in making the curriculum more relevant (reo, whaikorero, mihi, waiata, waiata-a-ringa, poi, haka, poroporoaki, whakapapa, karakia);

- the fact that attitudes to learning are also evaluated is very important.

\section{Comment:}

The percentages of Maori students in these schools ranged from $98 \%$ to 3\% and it was noted that in a number of schools the retention rate was increasing, perhaps due to a lack of jobs and the increasing relevance of senior schooling. The observations that follow seem to be more dependent on the school's commitment to its Maori students than on the size of its Maori roll. 
In approximately half these schools the achievement of Maori students is considered to be lower than the school norm. Unfortunately few schools undertake a detailed analysis of Maori achievement in order to identify appropriate action to improve this situation. Even when Maori achievement is on a par with that of non-Maori, detailed analyses seldom occur.

In the majority of reports which made some reference to the Maori content in each subject this was considered by reviewers to be inadequate. Systems to streng then biculturalism and provide for the particular needs of Maori students often required strengthening. Instances of some insensitive student attitudes towards Maori students were also observed. A typical comment was that the relevant expertise of the Maori staff was not always fully utilised by the school or shared with the staff.

\section{Report 3 [Education Review Office, 1993]}

From an analysis of 100 primary school review reports the following findings appeared most frequently along with typical reviewer comment on factors affecting Maori student achievement.

\section{Finding 1}

Reluctance to Monitor Progress of Maori Students as a Group

- The school is conscientiously monitoring the progress of individual children and the policy on assessment and evaluation is being followed and is reflected in daily practice. However there is a need for the school to monitor how well it is influencing Maori student achievement. The number of Maori children in the school is not high, but there is a disproportionate number of Maori children in the special needs programmes and this would suggest a concern if a number of Maori pupils are at risk in the key areas of language, reading and mathematics;

- As yet the school has no system in place specifically to track development of Maori children as a group. Children are monitored as part of whole school programmes. They are generally felt by staff to be in the lower third of regular class achievement levels;
- There are no stated policies or plans for meeting the learning needs of Maori pupils and this makes it difficult to comment on their levels of achievement as a particular group.

\section{Finding 2}

Comparisons on the Basis of Individuals

- Teachers report that the attainments of Maori students are consistent with the overall patterns of achievement throughout the school. Although parents have identified the students who recognise their Maori culture no separate analysis of their progress or achievement is undertaken;

- The school has similar expectations of success for the Maori pupils as for other pupils in the school. Teachers were able to talk about their progress as individuals but had no system for the collective monitoring of the progress of the children as a group.

\section{Finding 3}

General School Recognition of Maori Language and Culture

- The school identifies its greatest success for Maori children in the developments which have taken place among children in the school's Maori immersion unit. They are children learning through a language rather than simply learning a language and this is reflected in their acquisition of basic processes in literacy and numeracy;

- The promotion of Maori language and culture throughout the school is advancing the recognition of and achievement of Maori students. They are responding with enthusiasm as evidenced in the use of te reo in class and the powhiri to welcome the review team. The range of achievements of Maori students was found to be the same as all other students in the school. 


\section{Finding 4}

Positive Learning Expectations

- An examination of the achievement levels of Maori pupils shows that they are achieving at levels comparable with that of other learners. The school is aware of the need to monitor the achievement of Maori pupils;

- Achievement levels of Maori students match those of the total student body. The school considers that its expectations for Maori students are shown by the school's mission statement. Teachers have been involved in professional development in taha Maori and this is reflected in classrooms both visually and in the use of te reo.

\section{Finding 5}

\section{Bilingual Units}

- The bilingual class operates on the basis of a whanau group including new entrants to standard two students. The support for Maori values, teaching styles and Maori language is maintained by the class teacher and the Kaiarahi Reo;

- $\quad$ The pupils were seen to be making progress consistent with pupils in the rest of the school. They were positive and enthusiastic about learning and able to contribute their skills to the cultural life of the whole school.

\section{Finding 6}

Other factors have also been identified in the reports

- Encouragement across a wider spectrum of school life;

- Notable achievements outside the school include: the participation and performances of the school's Maori and Pacific Island culture groups at the cultural festival; the end of year concerts; the music festival groups; performances in the orchestra and the speech contest; and local sports successes in the swimming carnival, softball, netball, rugby, soccer and athletics.
240 Wally Penetito

- Push for achievement

- Analysis of standardised tests indicates that senior Maori students have high levels of achievement. During the review it was apparent that the school has high learning expectations of Maori as well as other students, and that these are being met.

- Same treatment for all

- Apart from the daily Maori language programme there is no attempt to include Maori perspectives in any other curriculum area. Maori pupils have the same opportunities as other students as there is no perceived need for alternatives. Because all pupils are viewed as the one unit, there is no provision made to identify and so provide for the particular needs of Maori pupils.

- Appropriate use of resources

- The school has used its Maori language funding wisely in the building up of resources, in the payment of the teacher aide and the provision of a taha Maori programme. Throughout this decision making process there has been consultation with the Maori parent support group.

- Community involvement

- The Maori culture group is central to the school and Maori parents have effectively demonstrated to the school community that tikanga Maori belongs to the whole school not just to Maori families.

\section{Summary of Findings}

Out of the plethora of material the Education Review Office has collected to evaluate Maori education a number of significant findings keep presenting themselves:

- while some schools have excellent systems for data collection to identify Maori students and their achievements, there is apparently a general reluctance to keep any separate records of Maori achievement: 
- the shortage of skilled Maori teachers as role models and as teachers of the language is a major problem;

- in general, teaching programmes are not being appropriately evaluated. The same applies to the role, contributions, or expectations of personnel such as kaiarahi reo and resource teachers of Maori;

- where schools have consulted with their community, have been prepared to act on advice and make sensitive use of community resources, constructive and useful educational programmes have been found. In many cases, however, the activities being conducted are superficial. Most schools and classrooms are still mono-cultural; and

- consultation with iwi Maori (community and/or tangata whenua) is irregular but, where undertaken, very rewarding.

\section{Tentative Explanations}

The general reluctance of teachers to keep separate aggregated records of Maori student progress and achievement can be explained at one level as the general reluctance of the New Zealand population at large to differentiate on the basis of "race" or "culture". The issue is with the perception of Maori versus New Zealander. At another level many teachers have a problem with the notion of "separate" which connotes "different" and gets interpreted as "deficient". Teachers who hold to this latter view argue that they teach children and "whether they are black or white, male or female, Pakeha or Maori is immaterial". At a third level the problem is with aggregation. Aggregation is simply too difficult, too time consuming and generates more problems than solutions in a very busy classroom context. Most teachers do not have ready access to a computer, most do not have analytical or statistical training, and few would have the confidence or expertise to plan and carry out specialised programmes that would arise from the exercise of aggregation.

I am loath to continue in this vein. An explanation like that above is plausible and makes general good sense. The same kind of explanation could be applied to the other major findings. The problem is that one would have to keep asking "so what"? Explanations do not make a difference, actions do. It has been clearly established that one of the reasons Maori student progress and achievement is hindered is that teachers do not have the concrete evidence that Maori students as a group are failing in certain areas. It then becomes imperative that teachers acknowledge this failure on their part, where it occurs, and that they remedy the practice. However, this somewhat liberal approach to intervention has not worked to the advantage of Maori learners in the past; it is unlikely to in the future. The stance of the Education Review Office is that requirements, spelled out in contractual obligations, between the interested parties must be explicit, unambiguous, able to be carried out and evaluated.

In Maori education, a framework for the audit and review of provision recommends that the relationships between the main parties be stated clearly. It is not, however, the work of the Education Review Office to contribute to those requirements but rather for the parties to the contract. The responsibility of the Office is to evaluate the performance of delivery.

A cornerstone of the effectiveness of assurance audits, as stated earlier, is that contractual obligations are specific and clearly stated. Requirements in Maori education are legendary for their inexplicitness, lack of focus, ambiguity of purpose, and absence of clear lines of accountability for enforcing compliance.

\section{Conclusion}

Whatever else schools do, a single yet simple and fundamental fact remains; schools are responsible for educating all their students. In New Zealand today there are very few schools indeed that can justifiably claim to have lifted the majority of their Maori students to new intellectual heights, to have added to their students' cultural capital as Maori New Zealanders, and to have helped Maori students gain both necessary work and life skills so that they can survive in hope and with dignity.

Tu Tangata, te kohanga reo, kura kaupapa Maori, the Waitangi Tribunal have all helped to reveal mana Maori but the mainstream schooling system, in spite of the considerable progress that has been made over the past 30 years remains for Maori a virtual secret garden.

In that wonderful publication put out by the New Zealand Council for Educational Research in 1967, John Watson borrowed a line from a traditional Aotea waiata to name the monograph "Horizons of 
Unknown Power". The power of the Maori is certainly less unknown today but the horizon remains a problem. The last line of the waiata describes this potential as "an horizon not hitherto pierced". Improved standards, higher quality performance, and new benchmarks in Maori education urgently need to be publicly articulated.

The work of the Education Review Office, through Assurance Audits and Effectiveness Reviews, will help to substantiate and clarify what is working and what is not. Who picks up the challenge and how it is picked up is the work to be done now, if Maori education is to move toward what it means to be educated in Aotearoa/New Zealand.

\section{References}

Education Review Office Corporate Plan,1 October 1989 to 30 June 1990,1989

- Corporate Plan 1 July 1990 to 30 June 1991, 1990.

- Statement of Intent, 1992/93, 1992-1.

- Handbook of Contractual Obligations and Undertakings - Schools (October). This document is being updated and is due to be replaced early 1993, 1992-2.

- Review on Report Information Maori and Maori Learners, 1992-3.

- Overview Analysis of a Sample of Secondary School Reviews, 1992-4.

- Overview Analysis of Maori Achievement, State Primary and Integrated School Reports, 1 July to 30 September 1992, 1993.

Penetito, W. T., Glasson, J. and Thew L. 1991 Review Methodology “Keeping It Simple While Engaging With Complexity". Paper presented to 13th National Conference of NZARE, Dunedin.

Watson, John E. Horizons of Unknown Power - Some Issues of Maori Schooling. Wellington : New Zealand Council for Educational Research, 1967.

\section{The author}

Wally Penetito, is of Tainui extraction. He was brought up and received his first formal education in the Matamata district. He is a trained primary teacher and has taught in schools in the Waikato, Otara and Opotiki districts. In 1972 he was an exchange teacher in Essex, England. He is a graduate in education and sociology from Massey University and in 1983 was a recipient of the Commonwealth Relations Trust Fellowship and studied at the University of London. Since 1989 he has been in the Education Review Office, first as Manager Development and currently as Group Manager, Analytical Services. 